\title{
The importance of frequency in estimating labour market transition rates
}

\author{
Pedro Gomes
}

\section{Correspondence:}

pgomes@eco.uc3m.es

Universidad Carlos III de Madrid,

Economics Department, C/ Madrid

126, 28903 Getafe, Spain

\begin{abstract}
Labour market transition rates are typically estimated using survey data, which are mainly carried out at monthly or quarterly frequency. I argue that rates from surveys at different frequencies are not comparable, even if corrected for time aggregation. I estimate labour market transition rates using monthly and quarterly frequency CPS data. I apply a time-aggregation correction to make them comparable. I find notable differences in terms of levels and volatilities. While the continuous time-aggregation correction does not alter the unemployment decomposition using the monthly survey, it does so when using the quarterly survey.
\end{abstract}

Jel codes: $E 24 ; \mathrm{J} 60$

Keywords: Job-finding rate; Job-separation rate; Transition rates; Time-aggregation correction; Unemployment decomposition

\section{Introduction}

The macroeconomic analysis of the US labour market is commonly done using the Current Population Survey (CPS). The CPS is a monthly survey that allows for the estimation of the transition rates between employment, unemployment, and inactivity since 1976. Amongst others, it has been used by Blanchard and Diamond (1990), Shimer (2005), Elsby et al. (2009) or Fujita and Ramey (2009).

For several other countries, the comparable labour force survey is only carried at a quarterly frequency. Gomes (2012), Elsby et al. (2011) and Elsby and Smith (2010) have examined quarterly survey data from the United Kingdom, Silva and Vázquez-Grenno (2013) from Spain, and Hairault et al. (2012) from France ${ }^{1}$. Particularly noticeable are Petrongolo and Pissarides (2008), who compare the relative importance of job-finding and job-separation rates across countries using administrative data (France and United Kingdom) and data from quarterly surveys (Spain and United Kingdom) and from monthly surveys (United States).

The different frequency of surveys poses the question of how comparable the transition flows between employment, unemployment, and inactivity are. Shimer (2005) and, more specifically, Shimer (2012) propose a methodology to correct for time aggregation. This correction is made defining the length of the time unit (say a week), making a partition of the frequency period in the time units (a month is formed by 4 weeks), assuming a constant transition rate between every two states for each time unit, and adding up the

(c) 2015 Gomes; licensee Springer. This is an Open Access article distributed under the terms of the Creative Commons Attribution License (http://creativecommons.org/licenses/by/4.0), which permits unrestricted use, distribution, and reproduction in any medium, provided the original work is properly credited. 
product of the transition rates for all the possible paths that link the initial state with the final state. To investigate the comparability of the data flows from datasets at different frequencies, it suffices to estimate the counterparts of the transition rates to the same time unit and verify whether they coincide.

Shimer (2012) argues that the time aggregation affects the cyclicality of transition rates and creates a bias when measuring the relative importance of job-finding and job-separation rates for unemployment fluctuations. He defends the use of a continuous time-aggregation correction that became a standard practice in the literature. Elsby et al. (2009) prefer the use of a discrete, weekly time-aggregation correction. Although they acknowledge Shimer's point, they find that the effect of the correction on the cyclicality of flows is quantitatively small. Nekarda (2009) further investigates the performance of the time-aggregation correction. Using weekly data from the Survey of Income and Program Participation, he is able to compute both the weekly and monthly transitions and check their consistency. He find that the monthly data understates the true transitions by 15 to 24 per cent. However, as in Elsby et al. (2009) he concludes that using the monthly data does not create a significant cyclical bias. This result was subsequently used by Smith (2011) to disregard the correction.

The objective of this paper, similar to Nekarda (2009), is to investigate how the frequency of a survey matters for measuring labour market flows and evaluate the performance of the time-aggregation correction. I calculate transition rates at monthly and quarterly frequency from the CPS between 1976 and 2011. I apply both the discrete and continuous time-aggregation corrections. As in Nekarda (2009), I find significant differences in the transition rates obtained at different frequencies, across all state pairs, both in terms of levels and volatilities. Using a quarterly survey understates the measured monthly transitions rates by 30 to 50 per cent.

I also evaluate whether the frequency of the survey affects the unemployment decomposition. Applying the continuous time-aggregation correction on the monthly survey data does not alter the relative importance of job-finding and job-separation rates, which is 50-50 in my sample. This result confirms the findings of Nekarda (2009) and Elsby et al. (2009). However, the data from the quarterly survey shows a different picture. Without correcting the data, the job-separation rate is measured to be more important (60-40), while the continuous time aggregation correction overstates the importance of the job-finding rate (40-60).

To understand these differences, the key insight is that the time-aggregation correction crucially imposes a within-period invariant transition rate as if transiting from one state to another were a memoryless stochastic process. Using the monthly survey, I calculate conditional transition probabilities that differ substantially depending on the previous labour market state. In the last section, I briefly discuss possible causes for history-dependent transition rates that have been identified in the labour literature.

\section{Theory of time aggregation}

This section follows closely the notation of Shimer (2012). Consider a labour market with three states: employment $(\mathrm{E})$, unemployment $(\mathrm{U})$, and inactivity (I). Each period $t \in\{0,1,2,3, .$.$\} corresponds to a month. A monthly survey observes the transitions$ between $t$ and $t+1$ recorded in a $3 \times 3$ discrete time Markov transition matrix $n_{m}$, with columns summing to 1 . A quarterly survey observes the transitions between $t$ and $t+3$ 
recorded in an equivalent transition matrix $n_{q}$. It is possible to extrapolate (and correct for the time-aggregation) the monthly transition matrix from the quarterly discrete transition matrix (and call it $\hat{n}_{m}$ ) as well as the quarterly transition matrix from the monthly discrete transition matrix (and call it $\hat{n}_{q}$ ). Let $\mu_{i}$ denote a diagonal matrix of eigenvalues and $p_{i}$ denote the matrix with corresponding eigenvectors of the discrete transition matrix at frequency $i \in\{m, q\}$. Then

$$
\begin{aligned}
& \hat{n}_{q}=n_{m} \times n_{m} \times n_{m}=p_{m} \mu_{m}^{3} p_{m}^{-1}, \\
& \hat{n}_{m}=p_{q} \mu_{q}^{1 / 3} p_{q}^{-1} .
\end{aligned}
$$

Suppose now that the transitions occur in a continuous time environment. Let $\lambda$ be the $3 \times 3$ continuous time Markov transition matrix that records in the off-diagonal the Poisson continuous arrival rate, $\lambda^{A B}$ from state $A \in\{E, U, I\}$ to state $B \neq A$. We can retrieve the continuous time transition matrix from the limit of either the monthly transition matrix (and call it $\hat{\lambda}_{m}$ ) or the quarterly transition matrix (and call it $\hat{\lambda}_{q}$ ).

$$
\begin{aligned}
& \hat{\lambda}_{m}=\lim _{\Delta \rightarrow 0} \frac{p_{m} \mu_{m}^{\Delta} p_{m}^{-1}-I}{\Delta}, \\
& \hat{\lambda}_{q}=\frac{1}{3} \lim _{\Delta \rightarrow 0} \frac{p_{q} \mu_{q}^{\Delta} p_{q}^{-1}-I}{\Delta} .
\end{aligned}
$$

The reason I divide by 3 in the latter expression is to make the two instantaneous rates comparable (total transitions per month). In the following section, I test using CPS data whether the discrete time extrapolated transition matrices are equal to the observed ones, $\hat{n}_{q}=n_{q}$ and $\hat{n}_{m}=n_{m}$, and whether the instantaneous rates also coincide, $\hat{\lambda}_{q}=\hat{\lambda}_{m}$.

\section{Transition rates at different frequencies}

I use CPS monthly data between 1976 and 2011 to compute the transition rates. The CPS surveys households for four consecutive months, leaves them out for 8 months, and interviews them again for four more months. Taking advantage of the CPS structure, we can compute the transition probabilities in the labour market by comparing the status of a worker in two different periods and then aggregating across individuals. I compare two consecutive waves to obtain monthly transition rates. The quarterly transition rates are derived by comparing the first and the forth waves and the fifth and eighth waves ${ }^{2}$. Throughout the paper, I refer to the quarterly survey to classify the frequency of the interviews ( $t$ and $t+3$ ) and not the frequency of the survey itself, which is monthly in both cases. All the original and treated series used in the paper, as well as the MATLAB codes for time-aggregation bias correction, are in an Additional file 1 (GomesIZA2015.zip, also available in the author's website). All series are shown in a Additional file 2: graphical appendix.

\subsection{Levels and volatilities}

Table 1 shows the off-diagonal elements of the matrices $n_{m}, \hat{n}_{m}, n_{q}$, and $\hat{n}_{q}$. The numbers of the extrapolated transitions are far from the directly observable ones. The extrapolated monthly rates have a downward bias that ranges from 30 to 50 per cent. Job-finding and job-separation rates are understated by one third, while the transitions in and out of inactivity have an even larger bias. From the extrapolated data, we would calculate an 
Table 1 Level and volatility of transition probabilities

\begin{tabular}{|c|c|c|c|c|c|c|}
\hline & \multicolumn{2}{|c|}{ Monthly } & \multicolumn{2}{|c|}{ Quarterly } & \multicolumn{2}{|c|}{ Continuous } \\
\hline & $\begin{array}{l}\text { Original } \\
n_{m}\end{array}$ & $\begin{array}{l}\text { Extrapolated } \\
\hat{n}_{m}\end{array}$ & $\begin{array}{l}\text { Original } \\
n_{q}\end{array}$ & $\begin{array}{l}\text { Extrapolated } \\
\hat{n}_{q}\end{array}$ & $\begin{array}{l}\text { Corrected } \\
\hat{\lambda}_{m}\end{array}$ & $\begin{array}{l}\text { Corrected } \\
\hat{\lambda}_{q}\end{array}$ \\
\hline \multicolumn{7}{|l|}{ Mean } \\
\hline$E \rightarrow U$ & 0.015 & 0.010 & 0.023 & 0.027 & 0.020 & 0.012 \\
\hline$E \rightarrow I$ & 0.029 & 0.015 & 0.046 & 0.086 & 0.358 & 0.213 \\
\hline$U \rightarrow E$ & 0.260 & 0.178 & 0.383 & 0.460 & 0.028 & 0.015 \\
\hline$U \rightarrow I$ & 0.221 & 0.120 & 0.259 & 0.376 & 0.312 & 0.145 \\
\hline$I \rightarrow E$ & 0.046 & 0.023 & 0.070 & 0.139 & 0.044 & 0.022 \\
\hline$I \rightarrow U$ & 0.026 & 0.013 & 0.027 & 0.044 & 0.036 & 0.015 \\
\hline \multicolumn{7}{|c|}{ Volatility } \\
\hline$E \rightarrow U$ & 0.0025 & 0.0018 & 0.0046 & 0.0058 & 0.0029 & 0.0020 \\
\hline$E \rightarrow I$ & 0.0026 & 0.0014 & 0.0039 & 0.0070 & 0.0728 & 0.0408 \\
\hline$U \rightarrow E$ & 0.0405 & 0.0295 & 0.0486 & 0.0456 & 0.0028 & 0.0014 \\
\hline$U \rightarrow I$ & 0.0240 & 0.0158 & 0.0248 & 0.0230 & 0.0481 & 0.0223 \\
\hline $\mathrm{I} \rightarrow \mathrm{E}$ & 0.0040 & 0.0020 & 0.0059 & 0.0110 & 0.0039 & 0.0020 \\
\hline $\mathrm{I} \rightarrow U$ & 0.0035 & 0.0016 & 0.0045 & 0.0085 & 0.0037 & 0.0017 \\
\hline
\end{tabular}

Note: Average transition rates and standard deviation from 1976:2 to 2011:6. $n_{m}$ and $n_{q}$ are the matrices calculated directly from CPS. $\hat{n}_{m}$ and $\hat{n}_{q}$ are calculated using equations (1) and (2). $\hat{\lambda}_{m}$ and $\hat{\lambda}_{q}$ are the continuous transition rates calculated using equations (3) and (4).

expected tenure of 40 months, compared to only 22 months using the original data ${ }^{3}$. The expected unemployment duration would be 5.6 months compared to 3.8 using the original data. The reverse side of the coin is the extrapolation of the quarterly rates (based on the monthly survey) that largely overestimate the actual rates. The upward bias ranges from 20 to 100 per cent. The same bias is observed in the standard deviation of the series.

Table 1 also shows the instantaneous transition rates, $\hat{\lambda}_{m}$ and $\hat{\lambda}_{q}$, as defined by expressions (3) and (4), as well as their volatilities. The differences between them are even larger than for the discrete rates. The average transition rates from and into inactivity calculated from the monthly survey are roughly twice as large as their quarterly-based counterparts. For the job-finding and job-separation rates the difference is around 60 per cent. The standard deviations are also substantially higher for the transitions obtained from the monthly survey. However the ratio of standard deviation to the mean is roughly proportional across the two sets.

\subsection{Unemployment decomposition}

As found by Nekarda (2009), the fact that the mean and volatility of transition rates are different does not imply a different cyclical pattern. To measure it, I perform an unemployment decomposition based on Shimer (2012). I first compute the three-states equilibrium unemployment rate calculated from both sets of continuous transition rates:

$$
\tilde{u}_{t, i}=\frac{\hat{\lambda}_{t, i}^{E I} \hat{\lambda}_{t, i}^{I U}+\hat{\lambda}_{t, i}^{I E} \hat{\lambda}_{t, i}^{E U}+\hat{\lambda}_{t, i}^{I U} \hat{\lambda}_{t, i}^{E U}}{\left(\hat{\lambda}_{t, i}^{E I} \hat{\lambda}_{t, i}^{I U}+\hat{\lambda}_{t, i}^{I E} \hat{\lambda}_{t, i}^{E U}+\hat{\lambda}_{t, i}^{I U} \hat{\lambda}_{t, i}^{E U}\right)+\left(\hat{\lambda}_{t, i}^{U I} \hat{\lambda}_{t, i}^{I E}+\hat{\lambda}_{t, i}^{I U} \hat{\lambda}_{t, i}^{U E}+\hat{\lambda}_{t, i}^{I E} \hat{\lambda}_{t, i}^{U E}\right)}, i \in\{m, q\} .
$$

Somewhat surprisingly, even with such distinct transition rates, the equilibrium unemployment based on the quarterly survey is basically indistinguishable from its monthlybased counterpart. They both track closely the actual unemployment rate, as shown in Figure 1. 


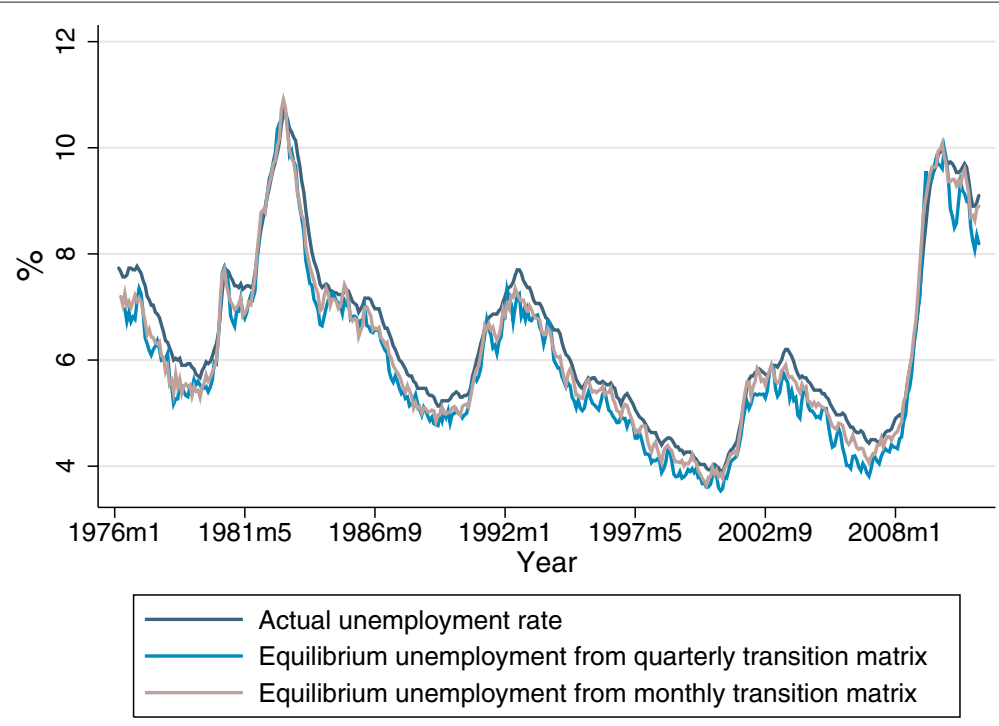

Figure 1 Unemployment rate. Note: All the series are a 3-month moving average.

The decomposition is based on a calculation of counterfactual unemployment rates, where all probabilities are kept constant at the sample mean, except one that is allowed to float. For instance, for the job-separation rate, we construct a counterfactual unemployment $\tilde{u}_{t, i}^{E U}=u\left(\hat{\lambda}_{t, i}^{E U}, \bar{\lambda}_{i}^{E I}, \bar{\lambda}_{i}^{U E}, \bar{\lambda}_{i}^{U I}, \bar{\lambda}_{i}^{I E}, \bar{\lambda}_{i}^{I U}\right)$ and measure its contribution by $\frac{\operatorname{Cov}\left(\tilde{u}_{t, i} \tilde{u}_{t, i}^{E L}\right)}{\operatorname{Var}\left(\tilde{u}_{t, i}\right)}$.

The results are reported in Table 2 . When using monthly survey data, the timeaggregation correction does not seem to matter for the decomposition. Both the original and corrected series have similar decompositions, with the job-finding rate only marginally more important than the job-separation rate, confirming the findings of Nekarda (2009) and Elsby et al. (2009).

The quarterly survey provides another conclusion. Using the original data, the jobseparation rate is more important, with roughly a 60-40 split. However, the continuous

Table 2 Unemployment decomposition

\begin{tabular}{|c|c|c|c|c|c|c|}
\hline & Mo & survey & & Quart & survey & \\
\hline & Original & Corrected & Original & & Corrected & \\
\hline & & Continuous & & Monthly & Weekly & Continuous \\
\hline & $n_{m}$ & $\hat{\lambda}_{m}$ & $n_{q}$ & $\hat{n}_{m}$ & $\hat{n}_{w}^{*}$ & $\hat{\lambda}_{q}$ \\
\hline$E \rightarrow U$ & 0.312 & 0.301 & 0.412 & 0.332 & 0.293 & 0.247 \\
\hline$E \rightarrow I$ & -0.001 & -0.001 & -0.002 & -0.004 & -0.004 & 0.001 \\
\hline$U \rightarrow E$ & 0.335 & 0.340 & 0.277 & 0.387 & 0.442 & 0.392 \\
\hline$U \rightarrow I$ & 0.105 & 0.107 & 0.073 & 0.109 & 0.125 & 0.106 \\
\hline $\mathrm{I} \rightarrow \mathrm{E}$ & 0.086 & 0.087 & 0.062 & 0.059 & 0.055 & 0.097 \\
\hline$I \rightarrow U$ & 0.164 & 0.166 & 0.177 & 0.117 & 0.090 & 0.158 \\
\hline
\end{tabular}


time-aggregation correction overcompensates, giving a 40-60 split in favour of the jobfinding rate. I investigate two alternative discrete corrections: a monthly and a weekly (based on Elsby et al. (2009)). Out of the two, the monthly discrete correction provides results that are more consistent with the monthly survey.

\section{Understanding the differences}

One key assumption of the time-aggregation correction is that the transition rates remain constant within the period. I now check whether the discrepancies found in the previous section result from the failure of this assumption. Using the transition matrices in discrete time, assume that the transition rates in the second and third month $\hat{n}_{m 2}$ are potentially different from the ones in the first month:

$$
n_{m} \times \hat{n}_{m 2} \times \hat{n}_{m 2}=n_{q} \Rightarrow \hat{n}_{m 2}^{2}=\left(n_{m}\right)^{-1} n_{q} .
$$

I retrieve the matrix $\hat{n}_{m 2}$ in two steps. First, I write its canonical form and multiply it by itself. Then I do the spectral decomposition of the matrix $\left(n_{m}\right)^{-1} n_{q}$. Because of expression (6) and the uniqueness of the spectral decomposition, I derive the eigenvalues and eigenvectors of the matrix $\hat{n}_{m 2}$. I report its off-diagonal numbers in the first column of Table 3. For comparability, the second column shows the numbers of matrix $n_{m}$. For $n_{m}$ and $n_{q}$ to be consistent, the transition rates in the second and third month have to be substantially lower. The job-separation rate has to be roughly half and the job-finding rate less than one half.

To have a deeper sense of these insights, I compute the monthly transition rates conditional on the labour market status in the previous period as in Gomes (2012). I calculate three transition matrices from time $t$ to $t+1$, each one conditional on a different state at time $t-1$. There are substantial differences in conditional rates. For instance, the employment-to-unemployment rate is $1.2 \%$ if the person was employed in the previous month, $13 \%$ if she was previously unemployed, and $4 \%$ if inactive. The job-finding rate is $43 \%$ if the job seeker was employed in the previous period but around $20 \%$ if unemployed or inactive. These differences are consistent with the gaps between the first two columns of Table 3. The bottom line is that transition flows cannot be treated as driven by a memoryless stochastic process. On the contrary, there are substantial history-dependent effects.

These findings are in line with Elsby et al. (2013). They estimate the monthly job-finding rates for OECD countries building upon the methodology of Shimer (2012) using data on the unemployed by different duration spells. They find that the calculated rates are

Table 3 Understanding the differences

\begin{tabular}{llllcl}
\hline & 2nd, 3rd Month & Unconditional & \multicolumn{3}{c}{ Conditional on: } \\
\hline & $\hat{n}_{m 2}$ & $n_{m}$ & $E_{t-1}$ & $U_{t-1}$ & $I_{t-1}$ \\
$\mathrm{E} \rightarrow \mathrm{U}$ & 0.008 & 0.015 & 0.012 & 0.132 & 0.038 \\
$\mathrm{E} \rightarrow \mathrm{I}$ & 0.008 & 0.029 & 0.019 & 0.076 & 0.277 \\
$\mathrm{U} \rightarrow \mathrm{E}$ & 0.119 & 0.260 & 0.439 & 0.207 & 0.194 \\
$\mathrm{U} \rightarrow \mathrm{I}$ & 0.062 & 0.221 & 0.133 & 0.166 & 0.403 \\
$\mathrm{I} \rightarrow \mathrm{E}$ & 0.013 & 0.046 & 0.340 & 0.126 & 0.026 \\
$\mathrm{I} \rightarrow \mathrm{U}$ & 0.001 & 0.026 & 0.066 & 0.261 & 0.016 \\
\hline Note: averages between 1976:2 and 2011:6, calculated from CPS. $\hat{\boldsymbol{n}}_{\boldsymbol{m} \mathbf{2}}$ calculated using equation (6).
\end{tabular}

Note: averages between 1976:2 and 2011:6, calculated from CPS. $\hat{\boldsymbol{n}}_{m 2}$ calculated using equation (6). 
statistically different depending on which unemployment length was used. In a companion paper, Hobijn and Sahin (2009) report that the US monthly job-finding rate is $42 \%$ for unemployment spells shorter than 1 month, whereas it falls to $31 \%$ when considering spells between 1 to 3 months and to $13 \%$ with spells between 3 to 6 months.

There are a several reasons for why the aggregate conditional probabilities are so different. Here, I briefly comment on four of them: ex-ante heterogeneity, ex-post heterogeneity, country specific characteristics and response-error bias.

\subsection{Ex-ante heterogeneity}

Workers are heterogeneous in many observable and unobservable characteristics that are time-invariant to a large extent, such as education, sex, and ability. If the transition rates differ across such dimensions, the aggregate rate might vary because of composition variation of the pool of workers. Suppose that there are only two states $A$ and $B$ and two groups of workers, type 1 and type 2 . These workers only differ in their transition rates from state $A$ to state $B$, with continuous time rates satisfying $\lambda_{1}^{A B}>\lambda_{2}^{A B}$. Then the observed average rate would decrease over time because the pool of workers in state $A$ would be increasingly formed by type 2 workers, who have a lower outflow rate. The empirical labour literature refers to this mechanism that explains falling job-finding rates as spurious negative duration dependence.

\subsection{Ex-post heterogeneity}

Even in the absence of ex-ante heterogeneity, ex-post heterogeneity may result from a number of history-dependent causes and make the aggregate transition rates differ across histories. For instance, if general and job-specific human capital accumulates (depreciates) when employed (unemployed), the probability of becoming unemployed (employed) may vary with tenure (unemployment duration) (Laureys 2013). Stigma and search discouragement are alternative mechanisms the empirical literature has identified as causes of state-dependent negative duration. See, e.g., Gonzalez and Shi (2010) and Fernandez-Blanco and Preugschat (2012).

\subsection{Country specific characteristics}

In the United States, on average, since 1990, 13 per cent of the unemployed are on temporary layoff. They expect to be called back by their former employer. Fujita and Moscarini (2013) document that nearly 40 percent of all job-seekers are rehired by the same employer, whereas this percentage rises to 85 percent for those temporary laid-off. Although this is neither an inherent characteristic of the worker nor duration-dependent, it is certainly the case that temporary laid-off workers experience different transition patterns. Calculations from the CPS show that the probability of finding a job within a month is 45 per cent for the temporary laid-off and 23 per cent for the other unemployed. Also, the probability of going to inactivity is roughly half compared to the regular unemployed. Temporary layoffs are more likely to be captured in monthly surveys than in quarterly ones since many employment-unemployment-employment transitions take place in weeks when temporary layoffs are involved.

While temporary layoffs are less relevant outside the United States, features of the institutional environment in Europe might also create duration dependence. Suppose that, as in many European countries, there are two types of contracts, permanent 
and temporary, with different separation rates (as analysed in Silva and VázquezGrenno 2013). The longer the employment spell the lower the job-separation rate would be because the pool of employment would be increasingly formed by permanent contracts.

\subsection{Response error bias}

When using survey data to estimate worker flows, there is the additional problem of response-error bias. The response-error bias may be severe because the errors are cumulative in longitudinal data and lead to an overestimation of flows. This bias is present irrespective of the frequency and should have the same magnitude. However, the bias should be larger relative to actual transitions in a monthly survey because there are few recorded transitions there. This bias might be particularly relevant for the transitions between unemployment and inactivity, which are more prone to be misreported. But, because the time-aggregation correction is computed with all the elements of the transition matrix, all the continuous rates are affected.

\section{Conclusion}

I show that even correcting for time aggregation, transition rates calculated from the CPS at monthly and quarterly frequencies are different in terms of levels and volatility. While the time-aggregation correction does not affect the unemployment decomposition using monthly survey data, it does so when using the quarterly survey. Several elements can contribute to these differences: ex-ante and ex-post heterogeneity, country specific characteristics, and response-error bias in surveys.

The main result is important in three dimensions. First, we should be aware of it when comparing labour market facts obtained from data sources with different frequencies. This is particularly relevant for cross-country comparisons, particularly between European countries and the United States, as in Petrongolo and Pissarides (2008), Elsby et al. (2011), Silva and Vázquez-Grenno (2013), or Hairault et al. (2012). Whenever a quarterly survey is used, the size of the transition rates should be compared to the quarterly CPS numbers provided here.

Second, while the time-aggregation correction might be disregarded for unemployment decomposition in a monthly survey, it is important when using a quarterly survey. It seems, however, that a continuous correction somehow overstates the importance of the job finding rate. In the particular case studied, a discrete monthly correction provides more consistent results.

The result also has implications for labour market models and their calibration. While the two sets of numbers at monthly and quarterly frequency are inconsistent, they are both valid, and it is not clear which one should be preferred. If the inconsistency is only due to the presence of heterogeneity, ideally, we should model the heterogeneity and match the labour market at several frequencies ${ }^{4}$. When the heterogeneity is not modeled, the quarterly numbers put a larger weight on people with lower transition rates, so perhaps the monthly numbers are more suited. However, if a significant fraction of the discrepancy is due to temporary layoffs and response-error bias, the monthly transitions might overstate the actual labour market flexibility. Disentangling the potential causes was not the objective of this paper. It is a difficult task but worthwhile pursuing. 


\section{Endnotes}

${ }^{1}$ The latter paper also computes the monthly transitions based on administrative data. Also worth mentioning are Hertweck and Sigrist (2015), who compute the monthly transitions for Germany.

${ }^{2}$ I extend Shimer's code, which is publicly available in his webpage. There are five breaks in the survey: $1978 \mathrm{~m} 1,1985 \mathrm{~m} 7,1985 \mathrm{~m} 10,1994 \mathrm{~m} 1$ and $1995 \mathrm{~m} 6$ to $1995 \mathrm{~m} 9$. The missing values are extrapolated by computing the average of the same month of the previous and following year. All the series were then seasonally adjusted using US Census Bureau X12.

${ }^{3}$ If we consider only the outflow of employment to unemployment, the calculated job tenure would be of 8.3 years using extrapolated data and 5.5 years using the original series.

${ }^{4}$ One interesting attempt is Morchio (2015). He documents that 10 per cent of individuals account for two thirds of all unemployment spells in the United States. He then sets up a model feature worker unobserved heterogeneity and match quality heterogeneity. He identifies the heterogeneity by looking at inequality in unemployment over the lifetime.

\section{Additional files}

Additional file 1: GomesIZA2015.zip (STATA \& MATLAB codes and data).

Additional file 2: Appendix.pdf (Graphical appendix).

Abbreviations

CPS: Current Population Survey; E: Employed; I: Inactive; U: Unemployed.

\section{Competing interests}

The IZA Journal of Labor Economics is committed to the IZA Guiding Principles of Research Integrity. The author declares that he has observed these principles.

\section{Acknowledgement}

I would like to thank Javier Fernandez-Blanco and an anonymous referee for their comments. Financial support was provided by the Bank of Spain's Programa de Investigación de Excelencia.

Responsible editor: Pierre Cahuc

Received: 24 November 2014 Accepted: 9 February 2015

Published online: 26 March 2015

References

Blanchard OJ, Diamond P (1990) The cyclical behavior of the gross flows of U.S. workers. Brookings Pap Econ Act 21(2):85-156

Elsby M, Hobijn B, Sahin A (2013) Unemployment dynamics in the OECD. Rev Econ Stat 95(2):530-548

Elsby M, Michaels R, Solon G (2009) The ins and outs of cyclical unemployment. Am Econ JMacroeconomics 1(1):84-110

Elsby M, Smith J (2010) A Great Recession in the UK Labour Market: A Transatlantic Perspective. Nat Inst Econ Rev 214:R1-R12

Elsby M, Smith J, Wadsworth J (2011) The role of worker flows in the dynamics and distribution of UK unemployment. Oxford Rev Econ Policy 27(2):338-363

Fernandez-Blanco J, Preugschat E (2012) On the Effects of Ranking by Unemployment Duration. Mimeo, Universitad Autònoma de Barcelona

Fujita S, Moscarini G (2013) Recall and Unemployment. NBER working paper 19640

Fujita S, Ramey G (2009) The Cyclicality of Separation and Job Finding Rates. Int Econ Rev 50(2):415-430

Gomes P (2012) Labour market flows: facts from the United Kingdom. Labour Econ 19(2):165-175

Gonzalez F, Shi S (2010) An Equilibrium Theory of Learning, Search, and Wages. Econometrica 78(2):509-537

Hairault J-O, Le Barbanchon T, Sopraseuth T (2012) The Cyclicality of the Separation and Job Finding Rates in France. IZA discussion paper 6909

Hertweck M, Sigrist O (2015) The Ins and Outs of German Unemployment: A Transatlantic Perpective. Oxford Econ Pap. Forthcoming

Hobijn B, Sahin A (2009) Job-finding and separation rates in the OECD. Econ Lett 104(3):107-111

Laureys L (2013) The Cost of Human Capital Depreciation during Unemployment. Mimeo, Bank of England working paper 505 
Morchio I (2015) Information frictions, match quality and lifetime unemployment. Mimeo, Universidad Carlos III de Madrid Nekarda C (2009) Understanding Unemployment Dynamics: The Role of Time Aggregation. Mimeo, Federal Research Board of Governors

Petrongolo B, Pissarides C (2008) The Ins and Outs of European Unemployment. Am Econ Rev 98(2):256-62

Shimer R (2005) The Cyclical Behavior of Equilibrium Unemployment and Vacancies. Am Econ Rev 95(1):25-49 Shimer R (2012) Reassessing the Ins and Outs of Unemployment. Rev Econ Dyn 15(2):127-148

Silva J, Vázquez-Grenno J (2013) The ins and outs of unemployment in a two-tier labor market. Labour Econ 24(C):161-169 Smith JC (2011) The Ins and Outs of UK Unemployment. Econ J 121(552):402-444

Submit your manuscript to a SpringerOpen ${ }^{\odot}$ journal and benefit from:

- Convenient online submission

$\rightarrow$ Rigorous peer review

- Immediate publication on acceptance

- Open access: articles freely available online

- High visibility within the field

- Retaining the copyright to your article

Submit your next manuscript at $\boldsymbol{\triangleright}$ springeropen.com 